\title{
Childhood Stress, Serotonin Transporter Gene and Brain Structures in Major Depression
}

\author{
Thomas Frodl*,',2, Elena Reinhold ${ }^{1,2}$, Nikolaos Koutsouleris², Gary Donohoe', Brigitta Bondy', \\ Maximilian Reiser ${ }^{3}$, Hans-Jürgen Möller $^{2}$ and Eva M MeisenzahI ${ }^{2}$ \\ 'Department of Psychiatry, Institute of Neuroscience, Trinity College, Dublin, Ireland; '2Department of Psychiatry, \\ Ludwig-Maximilians-University, Munich, Germany; ${ }^{3}$ Department of Radiology, Ludwig-Maximilians-University, Munich, Germany
}

\begin{abstract}
The underlying neurobiology of major depression (MD) is likely to represent an interaction between genetic susceptibility and environmental factors such as stress. We investigated, in a multimodal high-resolution magnetic resonance imaging (MRI) genetic study, whether reduced hippocampal volumes and other brain alterations are associated with the tri-allelic polymorphism of the serotonin transporter and childhood stress in patients with MD and healthy subjects. Patients with MD and healthy participants were investigated using high-resolution $\mathrm{MRI}$ and genotyping for serotonin transporter polymorphism in the promoter region of the serotonin transporter gene (SLC6A4, 5-HTTLPR). Region of interest analysis of the hippocampus, whole-brain voxel-based morphometry (VBM), and assessment of childhood stress were carried out. Patients carrying the risk S-allele developed smaller hippocampal volumes when they had a history of emotional neglect compared with patients who only had one risk factor (environmental or genetic). In patients, childhood stress also predicted further hippocampal white matter alterations independently from the genotype. Moreover, the left prefrontal cortex was smaller in patients, whereby childhood stress resulted in larger prefrontal volumes in those subjects carrying the non-risk L-allele, suggesting preventive effects. The findings indicate that subjects with both environmental and genetic risk factors are susceptible to stress-related hippocampal changes. Structural brain changes due to stress represent part of the mechanism by which the illness risk and outcome might be genetically mediated.

Neuropsychopharmacology (2010) 35, I383-1390; doi:10.1038/npp.20 10.8; published online 10 February 2010
\end{abstract}

Keywords: major depression; childhood stress; 5-HTTLPR; hippocampus; gene-environment

\section{INTRODUCTION}

Major depression (MD) is one of the most common human diseases, with a lifetime prevalence of $16 \%$ and a 12 -month prevalence of $6.6 \%$ (Kessler et al, 2003). A recent metaanalysis on 14250 participants showed that stressful life events have a potent association with the risk of developing depression (Risch et al, 2009). The underlying neurobiology of MD can be understood as the interaction of genetic susceptibility and environmental factors. On the basis of the meta-analysis, the serotonin transporter promoter polymorphism (5-HTTLPR) does not additionally seem to enhance the risk for MD in subjects with critical life events (Risch et al, 2009). However, it may still be a matter of debate whether early-life stress and the 5-HTTLPR may interact as shown by Caspi et al (2003). Moreover, an increased risk for MD was also detected in maltreated

\footnotetext{
*Correspondence: Professor T Frodl, Department of Psychiatry, Institute of Neuroscience, Trinity College, Dublin, Dublin 2, Ireland, Tel: + 3531896 8484, Fax: + 3531896 1000,

E-mail: frodlt@tcd.ie

Received 6 November 2009; revised 16 December 2009; accepted

9 January 2010
}

children homozygous for the short (S)-allele (Kaufman et al, 2006). Early-life neglect and abuse produce long-lasting emotional problems (Heim and Nemeroff, 2001). Experimental animal studies have shown stress-related neuroplastic changes in the brain that reverse under effective antidepressant treatment (McClung and Nestler, 2008). In line with this hypothesis, neuroimaging studies have shown that the hippocampus is about $4-5 \%$ smaller in patients with MD than in healthy controls, and that reduced hippocampal volumes are consistently found in MD (Campbell et al, 2004; Frodl et al, 2008d; Videbech and Ravnkilde, 2004). These hippocampal alterations are clinically relevant, because subjects who enter remission have larger hippocampal volumes than those who do not achieve remission (for review see MacQueen, 2009). In addition, pediatric patients with familial MDD showed decreased hippocampal volumes, indicating that reduced hippocampal volume may be present at very early stages and may be suggestive of a risk factor for developing MDD (MacMaster et al, 2008). In addition, volumes of other brain regions such as the prefrontal cortex, orbitofrontal cortex, gyrus cinguli, and the basal ganglia had been found to be reduced in patients with MD compared with healthy controls (Frodl et al, 2008d). 
Three studies reported that these hippocampal volume reductions and basal ganglia abnormalities are influenced by 5 -HTTLPR in patients with depression (Frodl et al, 2008d). The diallelic L/L genotype of the 5-HTTLPR was associated with smaller hippocampal volumes in 40 patients with MD and was not associated in 40 healthy controls (Frodl et al, 2004b). Moreover, 63 patients with a late-onset geriatric depression who were homozygous for the L-allele of the 5-HTTLPR exhibited smaller hippocampal volumes than those with other genotypes, whereas a significant association between the S-allele and smaller hippocampal volumes was observed in 72 patients with an early age of onset (Taylor et al, 2005). Another study did not find a significant association between 5-HTTLPR and hippocampal or amygdala volumes in 45 patients with $\mathrm{MD}$, whereas the short allele of 5-HTTLPR was associated with smaller caudate nucleus volumes (Hickie et al, 2007).

However, so far the interaction between environmental factors, genetic susceptibility, and brain changes has not been investigated in patients with MD. The aim of this study was to investigate whether reduced hippocampal and prefrontal volumes in patients with MD are associated with 5-HTTLPR and childhood stress either independently or interactively.

Therefore, we indexed brain volume using magnetic resonance imaging (MRI), voxel-based morphometry (VBM), a well-established method, as well as manual tracing of the hippocampus. We used the well-validated childhood trauma questionnaire (CTQ), which assesses trauma in terms of emotional neglect, emotional abuse, physical abuse, sexual abuse, and physical neglect. We genotyped the $5-H T T L P R$ as previously described (Frodl et al, 2008b). To test our hypothesis, we undertook both regression analysis and repeated measures ANOVA.

\section{MATERIALS AND METHODS}

\section{Participants}

A total of 24 patients (aged 18-65 years) being treated for their first time as inpatients for MD at the Department of Psychiatry and Psychotherapy of the Ludwig-MaximiliansUniversity, Munich, were investigated with structural MRI and childhood stress. Psychiatric diagnoses were made according to DSM-IV criteria and the structured clinical interview for DSM-IV (SCID) (First et al, 1997, 2001; Wittchen et al, 1997), and were determined by a consensus of at least two psychiatrists. Clinical variables were documented using the 21-item Hamilton Depression Rating Scale (HDRS).

Patients were compared with 27 healthy control subjects from the local community who were matched for age (aged 18-65 years) and gender. Demographic variables and exclusion criteria were assessed using a standardized questionnaire. Neither the healthy controls nor their firstdegree relatives had a history of neurological or mental illness. Age, gender, handedness, and weight were similar in patients and controls. Patients drank less alcohol at the last time before investigation compared with healthy controls, because they were admitted to hospital (Table 1). At the time of MRI scanning, patients received the following medication: seven patients received serotonin reuptake
Table I Demographic and Clinical Data of Healthy Controls and Patients with an Episode of Major Depression

\begin{tabular}{|c|c|c|c|}
\hline & $\begin{array}{c}\text { Patients } \\
(n=24) \\
\text { Mean } \pm \text { SD }\end{array}$ & $\begin{array}{c}\text { Controls } \\
(n=27) \\
\text { Mean } \pm \text { SD }\end{array}$ & $\begin{array}{l}t \text {-Test }{ }^{\mathrm{a}} l \\
\chi^{2} \text {-test }{ }^{\mathrm{b}} \\
p \text {-value }\end{array}$ \\
\hline Age (years) & $43.8 \pm 11.9$ & $41.9 \pm 13.2$ & $0.58^{\mathrm{a}}$ \\
\hline Female/male* & $18 / 9$ & $|3 / 1|$ & $0.36^{\mathrm{b}}$ \\
\hline Weight (kg) & $65.0 \pm 12.5$ & $7|| \pm 15.0$. & $0.12^{\mathrm{a}}$ \\
\hline Age of onset (years) & $38.3 \pm 9.9$ & & \\
\hline Cumulative illness duration (months) & $31.3 \pm 39.3$ & & \\
\hline HDRS_baseline & $24.1 \pm 6.2$ & & \\
\hline
\end{tabular}

Mean and standard deviations $( \pm)$ are given. *No significant differences were found between patients and controls, as measured with the $t$-test or $\chi^{2}$-test.

inhibitors, seven received tricyclic antidepressants, three mirtazapine, four venlafaxine, two reboxetine, and one patient received no medication. Age, gender, weight, and alcohol consumption did not differ in healthy controls with the S-allele of 5-HTTLPR and those with the LL genotype. These variables as well as age of onset, cumulative illness duration, and HDRS did not differ in patients with the S-allele of 5-HTTLPR and those with the LL genotype.

A structured interview was used to assess medical history, trauma, and other exclusion criteria. Exclusion criteria for all subjects were previous head injury with loss of consciousness, earlier treatment with hydrocortisone, a history of alcohol or substance abuse, and neurological diseases. Comorbidity with other mental illnesses, for example, bipolar disorders or personality disorders, was also an exclusion criterion. None of the subjects had ever been treated with electroconvulsive therapy. Handedness was determined by the Edinburgh inventory (Oldfield, 1971).

Written informed consent was obtained from patients and controls after they had been given a detailed description of the study. The study was designed and performed in accordance with the ethical standards laid down in the Declaration of Helsinki and was approved by the local ethical committee.

\section{MRI Procedures}

Magnetic resonance imaging images were obtained (1.5 Tesla Magnetom Vision, Siemens, Erlangen, Germany) using a coronal T2- and proton density-weighted DualEcho-Sequence (TR $3710 \mathrm{msec} / \mathrm{TE} 22 / 90 \mathrm{msec}$; total acquisition time: $9 \mathrm{~min}$, number of acquisitions: 1; field of view (FOV) $230 \mathrm{~mm}$; matrix $240 \times 256$, slice thickness: $3 \mathrm{~mm}$ ) and a 3D-MPRAGE sequence (TR/TE $11.6 \mathrm{msec} / 4.9 \mathrm{msec}$; total acquisition time: 9 min, number of acquisitions: 1; FOV $230 \mathrm{~mm}$; matrix $512 \times 512$, slice thickness: $1.5 \mathrm{~mm}$ ). The commercial software package Analyze was used (ANALYZE, Biomedical Imaging Resource, Mayo Foundation, Rochester, MN) for further image processing, with size reduction from 16 to 8 bit and transformation to a uniform matrix of $256 \times 256$ on 192 slices of $1.0-\mathrm{mm}$ slice thickness. All data sets were realigned and resampled three 


\section{a}

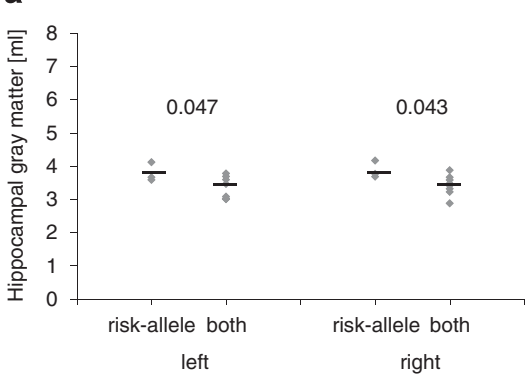

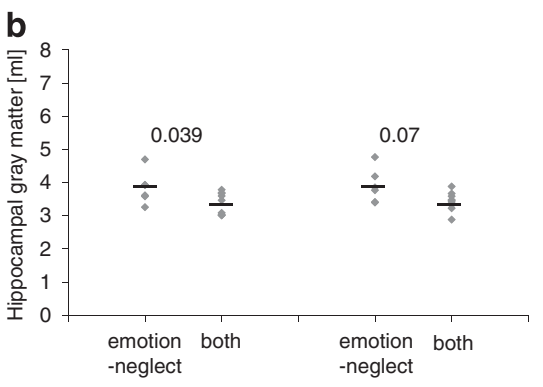

left

right

Figure I Patients carrying the risk S-allele developed smaller hippocampal volumes when they had suffered emotional neglect $(N=9)$ compared with those who had only one risk allele ( $N=6$ for emotional neglect and $\mathrm{N}=3$ for risk S-allele carrier). (a) Carriers of both risk factor versus carriers of only the genetic risk factor $-F=5.2, d f=I, I 3, p=0.039$. (b) Carriers of both risk factors versus carriers of only the environmental risk factor - $F=5.1, d f=I, I 0$, $p=0.048)$. P-values for the left and right hippocampal volume comparisons are also indicated.

dimensionally in the anterior commissure to posterior commissure (AC-PC) line, according to the coordinates of Talairach, using the software program BRAINS (Brain Research: Analysis of Images, Networks and Systems; developed by Andreasen et al (1992). The program BRAINS allowed the regions of interest (ROIs) to be controlled on sagittal and transverse sections simultaneously, and to be segmented to enable calculation of the intracranial content (ICC) and the gray and white matter (WM) volume $\left(\mathrm{ccm}^{3}\right)$ within the defined ROI. Software and hardware was not changed during the study.

\section{Definition of the Hippocampal Formation}

For a detailed description of the hippocampal borders, see Frodl et al (2002b). The description is illustrated in Figure 1. The evaluation staff (ER) was blind to subject status. The hippocampus was outlined manually using a mouse-driven cursor.

To determine inter-rater reliability, 10 brains were randomly chosen and ROIs determined by two raters (TF, ER) independently. The intraclass correlation for both the inter-rater reliability (hippocampus: $r_{\mathrm{ICC}}=0.97$ ) and the intra-rater reliability (hippocampus: $r_{\text {ICC }}=0.96$ ) was high (Frodl et al, 2002a, 2002b). Morphometric data were normally distributed.

\section{Voxel-Based Morphometry}

After manually reorienting and centering the images on the anterior commissure, data pre-processing was performed using the SPM5 software package (Wellcome Department of Cognitive Neurology, London, UK) running under MATLAB 6.5 (The MathWorks, Natick, MA).

The present study employed the VBM5 toolbox, which uses and extends the new unified segmentation approach implemented in SPM5 (Ashburner and Friston, 2005). Unified segmentation provides a generative model of VBM pre-processing that integrates tissue classification, image registration, and MRI inhomogeneous bias correction. Thus, the model avoids the 'circularity problem' of the optimized VBM procedure, as the initial image registration does not require an initial tissue segmentation and vice versa (Good et al, 2001). The VBM5 toolbox extends the unified segmentation model, as it increases the quality of segmentation by applying a Hidden Markov Field model on the segmented tissue maps (Cuadra et al, 2005).

The final tissue maps of gray matter (GM), WM, and cerebrospinal fluid were modulated with the deformation fields obtained by normalization to standard space to analyze volume differences between study populations. Finally, the modulated GM partitions were smoothed with a 12-mm FWHM Gaussian kernel and used for statistical analysis.

An analysis of covariance (ANCOVA) was designed to investigate focal gray matter volume (GMV) differences between the patients with MD and healthy controls, as well as between genotypes. Age and gender were entered as covariates of no interest in the statistical design. First, GM volume differences (increases/decreases) between patients with MD and healthy controls were assessed at the wholebrain level using $\mathrm{T}$ contrasts $(p<0.05$, FWE corrected).

To analyze the interaction between childhood stress as well as cumulative illness duration and genotype on the structural alterations, we extracted the eigenvariate from the significant resulting differences in GM volume and further used these data for statistical analysis.

\section{Childhood Stress}

The CTQ (Bernstein et al, 1994; Bernstein et al, 2003) was used to assess childhood stress. This questionnaire is a selfreport instrument that assesses five types of childhood maltreatment, namely, emotional, physical, and sexual abuse, and emotional and physical neglect. Subjects rate items about childhood experiences (defined as before the age of 18 years) on five-point Likert-type scales anchored by 'never true' and 'very often true.' Reliability and validity of the CTQ have been established, including measures of convergent and discriminate validity from structured interviews, stability over time, and corroboration (Bernstein et al, 1994; Bernstein et al, 2003).

\section{Genetics}

The DNA was extracted from a $5 \mathrm{ml}$ blood sample using the QIAamp Blood Isolation Kit (QIAGEN GmbH, Hilden, Germany) according to the supplier's instructions. We used the tri-allelic polymorphism SNP-rs25531 because the L-allele can be subtyped into La- and Lg-alleles, the latter 
of which is thought to be similar to the S-allele in terms of reuptake efficiency (Hu et al, 2005). Genotyping was carried out by applying the PCR amplification in a final volume of $25 \mu \mathrm{l}$ consisting of $50 \mathrm{ng} \mathrm{DNA}, 1 \mu \mathrm{mol} / 1$ of each primer, $200 \mu \mathrm{M}$ deoxynucleotide triphosphate, $100 \mu \mathrm{M}$ 7-deazaguanosine triphosphate, $5 \%$ dimethyl sulfoxide, $10 \mathrm{mM}$ Tris hydrochloride $(\mathrm{pH} 8.3), 50 \mathrm{mM}$ potassium chloride, $1.5 \mathrm{mM}$ magnesium chloride, and $2.5 \mathrm{U}$ of DNA polymerase (AmpliTaq Gold; PerkinElmer, Langen, Germany). The PCR products were separated on a $3 \%$ agarose gel (FMC NuSieve 3:1; Biozym Diagnostic GmbH, Oldendorf, Germany) and visualized by ethidium bromide staining.

\section{Statistical Analyses}

All statistical tests were considered to be significant if $p<0.05$. Morphometric measurements in both groups were normally distributed (using Kolmogorov-Smirnov test) and their variance was homogenous (using Levine's test). The genotypes of patients and controls were in Hardy-Weinberg equilibrium.

Hippocampal volumes were subjected to ANCOVA to assess the main and interaction effects of the withinsubjects factor, hemisphere (left, right), and the betweensubjects factors, diagnosis (depression, control) and gender (male, female), using total brain volume as the covariate. The whole-brain analysis for differences was carried out as described above.

To test our hypothesis that childhood stress and the 5-HTTLPR polymorphism are independently and interactively associated with hippocampal volume, we undertook both regression analysis and repeated measures ANOVA. Patients showed significantly increased values compared with healthy controls for emotional neglect $(\mathrm{t}=-2.1, \quad \mathrm{df}=1,49, \quad p=0.040) \quad$ and physical neglect $(\mathrm{t}=-2.5, \mathrm{df}=1,49, p=0.019)$; hence, we included these two items in the analysis as follows:

Hippocampal volumes were subjected to an ANOVA to assess the main and interaction effects of the withinsubject factor, hemisphere (left, right), and the betweensubject factors, diagnosis (depression, control), childhood stress (emotional neglect and physical neglect, high/low according to median split), and 5-HTTLPR (S-allele carriers, 11 homozygous). The same design, without the factor hemisphere, was used for the extracted left prefrontal lobe volumes.

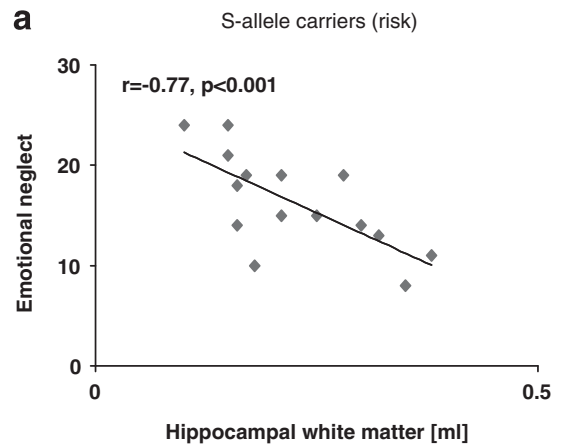

Linear multiple regression analyses were then used to examine whether childhood stress (emotional neglect or physical neglect) and 5-HTTLPR independently predicted hippocampal or prefrontal volumes in patients or controls. These analyses had two steps: (1) 5-HTTLPR (S-allele carriers, 11 homozygous) was regressed on hippocampal volumes. (2) Emotional neglect or physical neglect was regressed on the remaining hippocampal variance.

\section{RESULTS}

\section{Association between Stress, 5-HTTLPR, and Hippocampus}

There was no difference in hippocampal GMVs between patients and healthy controls and no significant hemisphere (left, right) effect. However, for patients, when subjects were grouped on the basis of (a) 5-HTTLPR polymorphism and (b) high versus low emotional neglect (based on a split halves cutoff) in the repeated measures ANOVA, an interaction between these variables was observed for hippocampal gray matter $(\mathrm{F}=7.1, \mathrm{df}=1,20, p=0.015)$. Patients who both carried the S-allele and had a positive history for emotional neglect developed smaller hippocampal volumes than patients with only one of these risk factors (Figure 1a and b). Hippocampal WM was significantly smaller in patients than in controls $(\mathrm{F}=16.3, \mathrm{df}=1,46$, $p<0.001)$. There was a significant interaction between diagnosis and 5-HTTLPR $(\mathrm{F}=8.2, \mathrm{df}=1,46, p=0.006)$, but no significant interaction between 5-HTTLPR and emotional neglect in patients $(p>0.05)$.

The regression analysis revealed that in the patient group, 5-HTTLPR polymorphism explained $33 \%$ of variance in hippocampal WM volume $\left(r_{\text {change }}^{2}=0.33 ; \quad \mathrm{F}_{\text {change }}=10.8\right.$, $\mathrm{df}=1,22, p=0.003 ; 95 \%$ CI: 0.04-1.6). After the effects of genotype were accounted for, emotional neglect independently accounted for a further $24 \%$ of variance in WM volume $\quad\left(\mathrm{F}_{\text {change }}=11.4, \mathrm{df}=1,21, p=0.003\right.$, Figure $2 \mathrm{a}$ and $b$ ). Together, these two variables, that is, 5-HTTLPR and emotional neglect, alone explained $57 \%$ of variance in hippocampal WM. In healthy volunteers, neither stress nor 5-HTTLPR polymorphism explained a significant proportion of variance in hippocampal volume $(p>0.05)$. The regression analysis did not show independent effects of 5-HTTLPR or childhood stress on hippocampal gray matter.

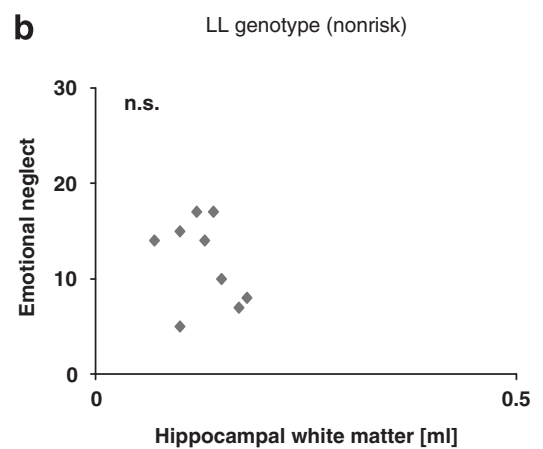

Figure 2 Childhood stress goes along with hippocampal reductions in genetically vulnerable patients carrying at least one short allele of the 5-HTTLPR. Scatterplots of total hippocampal volumes $(\mathrm{ml})$ and childhood stress. (a) S-allele carriers show significant negative correlations between hippocampal white matter and emotional neglect. (b) Childhood stress shows no significant association with hippocampal volumes in patients with the LL genotype. 
Association between Stress, 5-HTTLPR, and Prefrontal Cortex

A significant cluster for smaller GMVs in patients compared with healthy controls was detected in the left prefrontal cortex with extensions to the left orbitofrontal and to the pre-/postcentral cortices in the VBM $(p<0.05$, FWE corrected, Figure 3 ). There was a significant interaction between emotional neglect and 5-HTTLPR toward dorsolateral prefrontal volumes (DLPFC) $(\mathrm{F}=3.8, \mathrm{df}=1,50$, $p=0.05)$. Post hoc analysis indicated larger DLPFC in subjects homozygous for the L-allele, irrespective of being healthy or depressed, who had a history of emotional neglect compared with those without a history of emotional neglect $(\mathrm{F}=4.9, \mathrm{df}=1,15, p=0.04)$.

\section{DISCUSSION}

Evidence for the importance of epigenetic processes derives from the finding that the S-allele of the 5-HTTLPR affects susceptibility to hippocampal changes in the case of critical

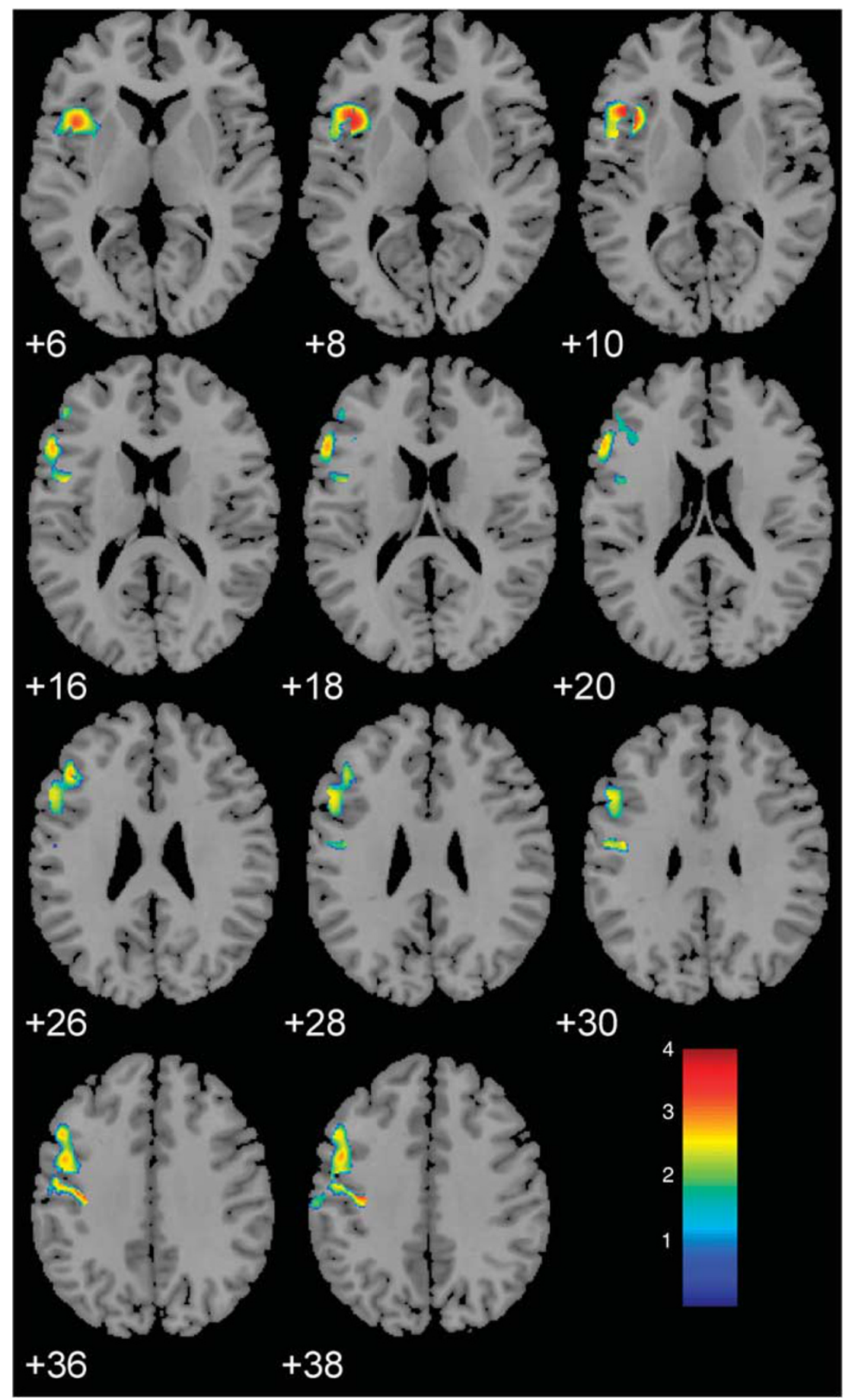

Figure 3 Voxel-based morphometry resulted a in significant smaller cluster for gray matter volumes within the left orbitofrontal-dorsolateral prefrontal cortex for patients compared with healthy controls (FWE corrected, $p<0.05$ ). 
stressful childhood events in patients with MD. This is important because it weaves disparate threads together into a coherent hypothesis of how susceptibility to depression might arise when the environment interacts with genetic factors to change neuroanatomy.

The gene-environmental interaction affected even the gray matter of the hippocampal formation, suggesting a disturbance of this structure in patients with MD who carry the genetic and the environmental risk factors compared with those, who only have one of these risk factors. Both of these two risk factors resulted independently in significant changes of the hippocampal WM, which seems to be more sensitive to subtle changes. The hippocampal WM mainly reflects the outgoing fibers of the fimbria to the additional structures of the limbic system. Therefore, these WM changes may be the result of an axonal reduction due to cell loss or to primary neuroplastic changes, which might favor cognitive as well as emotional disturbances during depression (McClung and Nestler, 2008).

Evidence for the importance of epigenetic processes also derives from a study in healthy controls using MRI, genotyping, and self-reported life stress. It could be shown that life stress affected, as a function of serotonin transporter genotype, the structural features of the gray matter, as well as functional connectivity of the amygdala and hippocampus with a wide network of other regions (Canli et al, 2006). Another recent study in healthy controls could show that Met-allele carriers of the BDNF polymorphism have smaller hippocampal volumes when they have elevations in stress as well as when they show more neuroticism (Joffe et al, 2009). In a recent study of 89 healthy participants, significant interactions between BDNF genotype and early-life stress were detected on hippocampal and amygdala volumes, heart rate, and working memory. Using structural equation modeling (SEM), the explicit pathways were investigated through which $B D N F$ genotype and early-life stress interact to produce effects on brain structure, body arousal, emotional stability, and in turn predict alterations in symptoms and cognition. SEM suggested that the combination of Met carrier status and exposure to early-life stress predicted reduced HC volumes, and, in turn, associated lateral prefrontal cortex volumes and higher depression (Gatt et al, 2009).

All these studies support the hypothesis that early-life stress and in addition interactive genetic variants contribute to smaller hippocampal volumes and, in turn, may then increase the risk to MD. These smaller hippocampal volumes, or of course the underlying neurobiological processes (for review see Dranovsky and Hen, 2006; Duman, 2004; Sapolsky, 2000) of these smaller hippocampal volumes, are clinically relevant. Hence, longitudinal studies showed an association between smaller hippocampal volumes and a worse clinical outcome (Frodl et al, 2008a; Frodl et al, 2004a). Moreover, patients with geriatric depression and small right hippocampal volumes were less likely to achieve remission compared with those with larger hippocampal volumes (Hsieh et al, 2002), and women who responded to 8 weeks of fluoxetine had larger right HC volumes than non-responders (Vakili et al, 2000). Smaller HC volumes also predicted low rates of remission in patients with no past treatment history, suggesting that the association between $\mathrm{HC}$ volumes and short-term clinical response was not simply a function of past treatment responsiveness (MacQueen et al, 2008).

Whereas 5-HTTLPR modulated the effects of childhood stress on hippocampal volumes, indicating that the hippocampus is a stress-sensitive brain region, this was different for the DLPFC. Subjects with more emotional neglect had larger prefrontal cortex volumes when they carried the non-risk allele. This effect was seen in the whole sample and was irrespective of diagnosis, suggesting that compensatory or preventive strategies could result in increased cortex volumes during development. Furthermore, this underlines the role of the serotonergic system in neuroplasticity and brain development, as discussed in the next section. The L-allele might have protective effects in subjects who had emotional neglect, in line with a study showing increased DLPFC in monkeys raised only together with monkeys in their age compared with monkeys raised in their families (Spinelli et al, 2009). In turn, this might correspond to the better response of those patients, who carry the L-allele, to antidepressant treatment (Serretti et al, 2007).

To bridge the gap between childhood stress, reduced structural brain volumes, and serotonin transporter polymorphisms, it is interesting to speculate, how specifically subjects might be vulnerable to develop smaller brain structures. With extreme or chronic stress, there are volumetric decreases in the hippocampal formation, with an increased vulnerability to metabolic insults, and even death of the CA3 region (Sapolsky, 2003). High levels of glucocorticoids (Woolley et al, 1990) or behavioral stress (Magarinos et al, 1996; Watanabe et al, 1992) result in atrophy and retraction of the apical dendrites of hippocampal pyramidal cells. Prolonged stress and increased levels of glucocorticoids also disrupt hippocampal neurogenesis (Dranovsky and Hen, 2006; Duman, 2004). Interestingly, the hippocampus is vulnerable to stress, particularly during the early developmental period (Teicher et al, 2003). In addition to its role as a neurotransmitter, serotonin acts as a trophic factor modulating developmental processes, such as neuronal division, differentiation, migration, synaptogenesis (Gaspar et al, 2003), early CNS development (Lauder, 1993), and adult neurogenesis (Gould, 1999). Considering the functional role of the serotonin transporter polymorphism-the S-allele of the HTTLPR shows decreased 5-HTT expression and decreased 5-HT-reuptake in vitro and in vivo (Bengel et al, 1998; Heinz et al, 2000; Lesch et al, 1996) - recent experimental studies on the interaction between serotonin and stress may be helpful for bridging the gap to the underlying mechanisms. Interestingly, early parental deprivation in marmoset monkeys, in the absence of subsequent stressors, already has a long-term effect on the hippocampal expression of genes implicated in synaptic function and plasticity, such as reductions of GAP-43 and serotonin 1A receptor expressions, which are comparable with findings in mood disorder. However, the stressor did not change the hippocampal volume (Law et al, 2009), supporting the view that hippocampal atrophy in mood disorder is not related to the early developmental component of pathogenesis, but is a correlate or consequence of the disorder (Czeh and Lucassen, 2007), or that other factors such as genetic factors might be necessary (Frodl et al, 2008c). The latter view is 
supported by another recent study. Serotonin transporter knockout rats had lower basal Arc mRNA levels, which is a marker for synaptic plasticity, in the hippocampus and prefrontal cortex and showed altered stress responsiveness compared with wild-type rats. Hence, an acute swim stress test significantly upregulated the levels of Arc mRNA in the hippocampus and prefrontal cortex, as well as of Zif-268, in the frontal cortex, only in mutant SERT( + /-) and SERT(-/-) rats (Molteni et al, 2009). For explanation, Arc is an immediate early gene that might bridge neuronal activity with structural remodeling and functional changes, and it is also thought to have a role in activity-dependent synaptic modifications (Bramham et al, 2008); Zif-268, also known as early growth response gene 1 (Egr-1), is tightly linked to neuronal plasticity (Knapska and Kaczmarek, 2004). Therefore, we might speculate that risk S-allele carriers show an enhanced stress response and increased neuroplastic changes due to early-life stress. This, in turn, might affect neuronal development and result in smaller hippocampal and prefrontal cortex volumes, as seen in the present study in humans.

A limitation of the present study is the relatively small sample size to conduct subgroup analysis with respect to lifetime illness course. It also has to be mentioned that abuse, in particular, sexual abuse, remains underreported, for example, in healthy individuals (McBeth et al, 2001). A bias caused by the acute depressive episode is unlikely, because we assessed the questionnaire after patients improved and were discharged from the hospital. The findings have to be confirmed with a larger sample in a prospective study.

For conclusion, the structural hippocampal brain changes due to stress represent part of the mechanism by which the illness risk to develop MD may be genetically mediated and, therefore, underline the importance of stress-gene-brain interactions in MD. These findings may also underline the need for psychotherapy in the treatment of MD and to find antidepressants that enhance neuroplasticity and result in a normalization of neuronal alterations.

\section{ACKNOWLEDGEMENTS}

Elena Reinhold carried out her doctoral thesis within this study.

\section{DISCLOSURE}

We declare that this work was supported by the German Federal Research Ministry within the promotion 'German Research Networks in Medicine' as part of the project 'German Research Network on Depression and by the Friedrich-Baur Institute Munich. None of the authors has a competing interest with regard to this manuscript. Professor Frodl has received compensations for presentation from Eli Lilly, Wyeth, and Janssen-Cilag. Professor Moeller has received grants or is a consultant for and on the speakership bureau of AstraZeneca, Bristol-Meyers Squibb, EISAI, Eli Lilly, GlaxoSmithKline, Janssen Cilag, Lundbeck, Merck, Novartis, Organon, Pfizer, Sanofi Aventis, Scherling-Pough, Schwabe, Sepracor, Servier, and Wyeth.

\section{REFERENCES}

Andreasen NC, Cohen G, Harris G, Cizadlo T, Parkkinen J, Rezai K et al. (1992). Image processing for the study of brain structure and function: problems and programs. J Neuropsychiatry Clin Neurosci 4: 125-133.

Ashburner J, Friston KJ (2005). Unified segmentation. Neuroimage 26: 839-851.

Bengel D, Murphy DL, Andrews AM, Wichems CH, Feltner D, Heils A et al. (1998). Altered brain serotonin homeostasis and locomotor insensitivity to 3, 4-methylenedioxymethamphetamine ('Ecstasy') in serotonin transporter-deficient mice. Mol Pharmacol 53: 649-655.

Bernstein DP, Fink L, Handelsman L, Foote J, Lovejoy M, Wenzel K et al. (1994). Initial reliability and validity of a new retrospective measure of child abuse and neglect. Am J Psychiatry 151: 1132-1136.

Bernstein DP, Stein JA, Newcomb MD, Walker E, Pogge D, Ahluvalia T et al. (2003). Development and validation of a brief screening version of the Childhood Trauma Questionnaire. Child Abuse Negl 27: 169-190.

Bramham CR, Worley PF, Moore MJ, Guzowski JF (2008). The immediate early gene arc/arg3.1: regulation, mechanisms, and function. J Neurosci 28: 11760-11767.

Campbell S, Marriott M, Nahmias C, MacQueen GM (2004). Lower hippocampal volume in patients suffering from depression: a meta-analysis. Am J Psychiatry 161: 598-607.

Canli T, Qiu M, Omura K, Congdon E, Haas BW, Amin Z et al. (2006). Neural correlates of epigenesis. Proc Natl Acad Sci USA 103: $16033-16038$.

Caspi A, Sugden K, Moffitt TE, Taylor A, Craig IW, Harrington H et al. (2003). Influence of life stress on depression: moderation by a polymorphism in the 5-HTT gene. Science 301: 386-389.

Cuadra MB, Cammoun L, Butz T, Cuisenaire O, Thiran JP (2005). Comparison and validation of tissue modelization and statistical classification methods in T1-weighted MR brain images. IEEE Trans Med Imaging 24: 1548-1565.

Czeh B, Lucassen PJ (2007). What causes the hippocampal volume decrease in depression? Are neurogenesis, glial changes and apoptosis implicated? Eur Arch Psychiatry Clin Neurosci 257: 250-260.

Dranovsky A, Hen R (2006). Hippocampal neurogenesis: regulation by stress and antidepressants. Biol Psychiatry 59: 1136-1143.

Duman RS (2004). Depression: a case of neuronal life and death? Biol Psychiatry 56: 140-145.

First M, Spitzer R, Gibbon M (1997). Structured Clinical Interview for DSM-IV Personality Disorders (SCID-II). American Psychiatric Press: Washington.

First M, Spitzer R, Gibbon M (2001). Structured Clinical Interview for DSM-IV-TR Axis I Disorders, Research Version. New York State Psychiatric Institute: New York.

Frodl T, Jager M, Smajstrlova I, Born C, Bottlender R, Palladino T et al. (2008a). Effect of hippocampal and amygdala volumes on clinical outcomes in major depression: a 3-year prospective magnetic resonance imaging study. J Psychiatry Neurosci 33: 423-430.

Frodl T, Koutsouleris N, Bottlender R, Born C, Jager M, Morgenthaler $\mathrm{M}$ et al. (2008b). Reduced gray matter brain volumes are associated with variants of the serotonin transporter gene in major depression. Mol Psychiatry 13: 1093-1101.

Frodl T, Meisenzahl E, Zetzsche T, Bottlender R, Born C, Groll C et al. (2002a). Enlargement of the amygdala in patients with a first episode of major depression. Biol Psychiatry 51: 708-714.

Frodl T, Meisenzahl EM, Zetzsche T, Born C, Groll C, Jager M et al. (2002b). Hippocampal changes in patients with a first episode of major depression. Am J Psychiatry 159: 1112-1118.

Frodl T, Meisenzahl EM, Zetzsche T, Hohne T, Banac S, Schorr C et al. (2004a). Hippocampal and amygdala changes in patients with major depressive disorder and healthy controls during a 1-year follow-up. J Clin Psychiatry 65: 492-499. 
Frodl T, Meisenzahl EM, Zill P, Baghai T, Rujescu D, Leinsinger G et al. (2004b). Reduced hippocampal volumes associated with the long variant of the serotonin transporter polymorphism in major depression. Arch Gen Psychiatry 61: 177-183.

Frodl T, Moller HJ, Meisenzahl E (2008c). Neuroimaging genetics: new perspectives in research on major depression? Acta Psychiatr Scand 118: 363-372.

Frodl T, Moller HJ, Meisenzahl E (2008d). Neuroimaging genetics: new perspectives in research on major depression? Acta Psychiatr Scand 118: 363-372 Epub 2008 Jul 14.

Gaspar P, Cases O, Maroteaux L (2003). The developmental role of serotonin: news from mouse molecular genetics. Nat Rev Neurosci 4: 1002-1012.

Gatt JM, Nemeroff CB, Dobson-Stone C, Paul RH, Bryant RA, Schofield PR et al. (2009). Interactions between BDNF Val66Met polymorphism and early life stress predict brain and arousal pathways to syndromal depression and anxiety. Mol Psychiatry 14: 681-695.

Good CD, Johnsrude IS, Ashburner J, Henson RN, Friston KJ, Frackowiak RS (2001). A voxel-based morphometric study of ageing in 465 normal adult human brains. Neuroimage 14(1 Pt 1): 21-36.

Gould E (1999). Serotonin and hippocampal neurogenesis. Neuropsychopharmacology 21(2 Suppl): 46S-51S.

Heim C, Nemeroff CB (2001). The role of childhood trauma in the neurobiology of mood and anxiety disorders: preclinical and clinical studies. Biol Psychiatry 49: 1023-1039.

Heinz A, Jones DW, Mazzanti C, Goldman D, Ragan P, Hommer D et al. (2000). A relationship between serotonin transporter genotype and in vivo protein expression and alcohol neurotoxicity. Biol Psychiatry 47: 643-649.

Hickie IB, Naismith SL, Ward PB, Scott EM, Mitchell PB, Schofield PR et al. (2007). Serotonin transporter gene status predicts caudate nucleus but not amygdala or hippocampal volumes in older persons with major depression. J Affect Disord 98: 137-142.

Hsieh MH, McQuoid DR, Levy RM, Payne ME, MacFall JR, Steffens DC (2002). Hippocampal volume and antidepressant response in geriatric depression. Int J Geriatr Psychiatry 17: 519-525.

Hu X, Oroszi G, Chun J, Smith TL, Goldman D, Schuckit MA (2005). An expanded evaluation of the relationship of four alleles to the level of response to alcohol and the alcoholism risk. Alcohol Clin Exp Res 29: 8-16.

Joffe RT, Gatt JM, Kemp AH, Grieve S, Dobson-Stone C, Kuan SA et al. (2009). Brain derived neurotrophic factor Val66Met polymorphism, the five factor model of personality and hippocampal volume: implications for depressive illness. Hum Brain Mapp 30: 1246-1256.

Kaufman J, Yang BZ, Douglas-Palumberi H, Grasso D, Lipschitz D, Houshyar S et al. (2006). Brain-derived neurotrophic factor-5HTTLPR gene interactions and environmental modifiers of depression in children. Biol Psychiatry 59: 673-680.

Kessler RC, Berglund P, Demler O, Jin R, Koretz D, Merikangas KR et al. (2003). The epidemiology of major depressive disorder: results from the National Comorbidity Survey Replication (NCS-R). JAMA 289: 3095-3105.

Knapska E, Kaczmarek L (2004). A gene for neuronal plasticity in the mammalian brain: Zif268/Egr-1/NGFI-A/Krox-24/TIS8/ ZENK? Prog Neurobiol 74: 183-211.

Lauder JM (1993). Neurotransmitters as growth regulatory signals: role of receptors and second messengers. Trends Neurosci 16: 233-240.

Law AJ, Pei Q, Walker M, Gordon-Andrews H, Weickert CS, Feldon J et al. (2009). Early parental deprivation in the marmoset monkey produces long-term changes in hippocampal expression of genes involved in synaptic plasticity and implicated in mood disorder. Neuropsychopharmacology 34: 1381-1394.

Lesch KP, Bengel D, Heils A, Sabol SZ, Greenberg BD, Petri S et al. (1996). Association of anxiety-related traits with a polymorphism in the serotonin transporter gene regulatory region. Science 274: 1527-1531.

MacMaster FP, Mirza Y, Szeszko PR, Kmiecik LE, Easter PC, Taormina SP et al. (2008). Amygdala and hippocampal volumes in familial early onset major depressive disorder. Biol Psychiatry 63: $385-390$.

MacQueen GM (2009). Magnetic resonance imaging and prediction of outcome in patients with major depressive disorder. J Psychiatry Neurosci 34: 343-349.

MacQueen GM, Yucel K, Taylor VH, Macdonald K, Joffe R (2008). Posterior hippocampal volumes are associated with remission rates in patients with major depressive disorder. Biol Psychiatry 64: 880-883.

Magarinos AM, McEwen BS, Flugge G, Fuchs E (1996). Chronic psychosocial stress causes apical dendritic atrophy of hippocampal CA3 pyramidal neurons in subordinate tree shrews. J Neurosci 16: 3534-3540.

McBeth J, Morris S, Benjamin S, Silman AJ, Macfarlane GJ (2001). Associations between adverse events in childhood and chronic widespread pain in adulthood: are they explained by differential recall? J Rheumatol 28: 2305-2309.

McClung CA, Nestler EJ (2008). Neuroplasticity mediated by altered gene expression. Neuropsychopharmacology 33: 3-17.

Molteni R, Calabrese F, Maj PF, Olivier JD, Racagni G, Ellenbroek BA et al. (2009). Altered expression and modulation of activity-regulated cytoskeletal associated protein (Arc) in serotonin transporter knockout rats. Eur Neuropsychopharmacol 19: $898-904$

Oldfield RC (1971). The assessment and analysis of handedness: the Edinburgh inventory. Neuropsychologia 9: 97-113.

Risch N, Herrell R, Lehner T, Liang KY, Eaves L, Hoh J et al. (2009). Interaction between the serotonin transporter gene (5-HTTLPR), stressful life events, and risk of depression: a meta-analysis. JAMA 301: 2462-2471.

Sapolsky RM (2000). Glucocorticoids and hippocampal atrophy in neuropsychiatric disorders. Arch Gen Psychiatry 57: 925-935.

Sapolsky RM (2003). Stress and plasticity in the limbic system. Neurochem Res 28: 1735-1742.

Serretti A, Kato M, De Ronchi D, Kinoshita T (2007). Meta-analysis of serotonin transporter gene promoter polymorphism (5HTTLPR) association with selective serotonin reuptake inhibitor efficacy in depressed patients. Mol Psychiatry 12: 247-257.

Spinelli S, Chefer S, Suomi SJ, Higley JD, Barr CS, Stein E (2009). Early-life stress induces long-term morphologic changes in primate brain. Arch Gen Psychiatry 66: 658-665.

Taylor WD, Steffens DC, Payne ME, MacFall JR, Marchuk DA, Svenson IK et al. (2005). Influence of serotonin transporter promoter region polymorphisms on hippocampal volumes in late-life depression. Arch Gen Psychiatry 62: 537-544.

Teicher MH, Andersen SL, Polcari A, Anderson CM, Navalta CP, Kim DM (2003). The neurobiological consequences of early stress and childhood maltreatment. Neurosci Biobehav Rev 27 33-44.

Vakili K, Pillay SS, Lafer B, Fava M, Renshaw PF, BonelloCintron CM et al. (2000). Hippocampal volume in primary unipolar major depression: a magnetic resonance imaging study. Biol Psychiatry 47: 1087-1090.

Videbech P, Ravnkilde B (2004). Hippocampal volume and depression: a meta-analysis of MRI studies. Am J Psychiatry 161: 1957-1966.

Watanabe Y, Gould E, McEwen BS (1992). Stress induces atrophy of apical dendrites of hippocampal CA3 pyramidal neurons. Brain Res 588: 341-345.

Wittchen H-U, Zaudig M, Fydrich T (1997). SKID-I und SKID-II, Strukturiertes Klinisches Interview für DSM-IV. Hogrefe: Gottingen.

Woolley CS, Gould E, McEwen BS (1990). Exposure to excess glucocorticoids alters dendritic morphology of adult hippocampal pyramidal neurons. Brain Res 531: 225-231. 